\title{
Levamisole-adulterated cocaine: a case of retiform purpura, cutaneous necrosis and neutropenia
}

\author{
Parinita A Dherange, Norman Beatty, Ahmad Al-Khashman
}

Department of Internal Medicine, Banner University Medical Center South, Tucson, Arizona, US

\section{Correspondence to} Parinita A Dherange, parinita.dherange@ bannerhealth.com

Accepted 8 July 2015
CrossMark

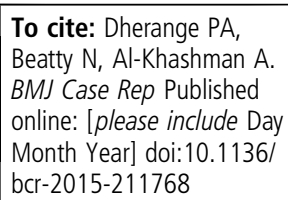

\section{DESCRIPTION}

A 53-year-old man presented to the emergency department with symptoms of bilateral ear pain that developed over the past $8 \mathrm{~h}$. The patient was a chronic cocaine user for the past 35 years and had last inhaled 'crack cocaine' on the day of presentation. On examination, both auricles were erythematous and painful to the touch (figure 1). Palpable, non-blanching retiform purpura were evident with a similar non-blanching erythematous patch on both cheeks (figure 2). The anterior portions of both lower extremities had developing purpura (figure 3). Skin necrosis was also found on the right hand (figure 4).

Initial laboratory findings showed leucopenia with isolated neutropenia, normal platelet count and normal complete metabolic panel. Urine toxicology was positive for cocaine. Coagulation panel was within normal limits. Further autoimmune work-up revealed perinuclear antineutrophil cytoplasmic antibodies ( $\mathrm{p}$-ANCA) positive and elevated IgM anticardiolipin antibodies with negative antinuclear antibodies. Hepatitis viral panel, cryoglobulins and HIV tests were negative. Based on his clinical picture, laboratory findings and a detected serum levamisole level, the diagnosis of drug-induced ANCA-associated vasculitis secondary to levamisole-adulterated cocaine was made. Rheumatology follow-up within 10 days showed complete resolution of the purpuric lesions on the ears and healing of the skin necrosis on the hand within 10 days of abstinence from cocaine.

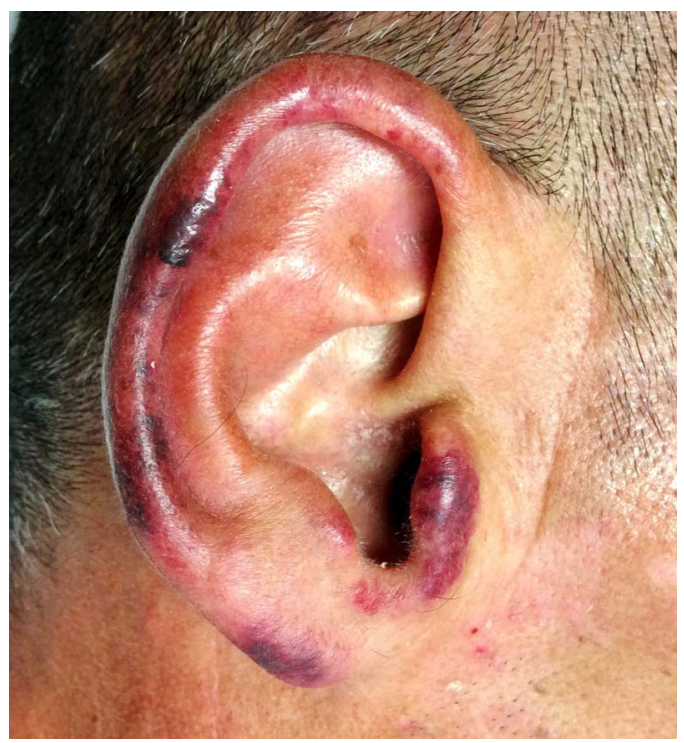

Figure 1 Right auricle with haemorrhagic and necrotic lesions in levamisole-associated vasculitis.

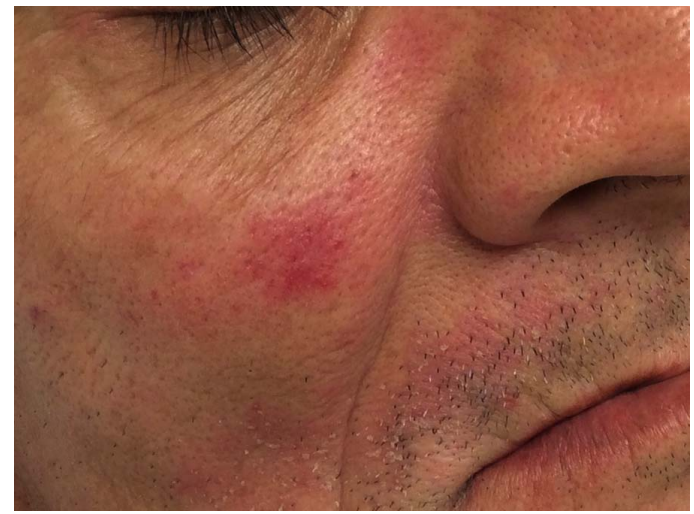

Figure 2 Characteristic retiform purpura noted on right cheek.

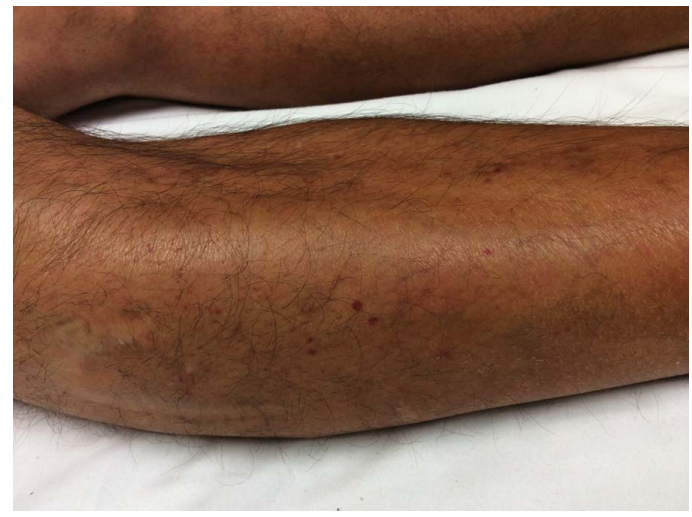

Figure 3 Small purpuric lesions on lower extremities.

Levamisole is an anthelmintic drug banned for human use in most countries after reported serious side effects, most notably agranulocytosis. ${ }^{1}$ It can also be used as an immunomodulator and

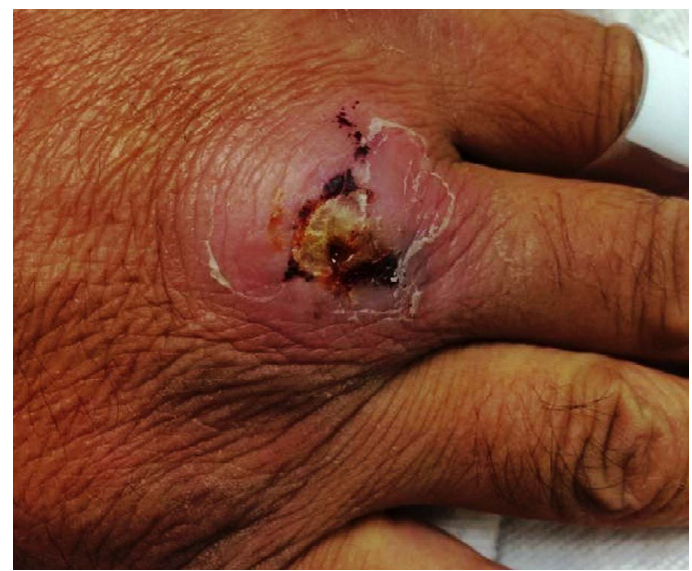

Figure 4 Skin necrosis present on the right hand. 
chemotherapy adjuvant. Since 2005, complications from snorting and or inhaling cocaine contaminated with levamisole have been drastically increasing throughout the world. ${ }^{1}$ Currently, the US Drug Enforcement Agency estimates that levamisole is present in at least $80 \%$ of all cocaine in North America. ${ }^{2}$ Furthermore, increasing levels are being detected in Europe and Asia. It is unclear how levamisole in the presence of cocaine results in disease, although it is thought that it could serve as a substrate for myeloperoxidase to form reactive metabolites that might stimulate autoimmunity. ${ }^{3}$ Clinical features include retiform purpura with a distinguished propensity for the auricles, nose and face, cutaneous necrotic lesions and agranulocytosis.

\section{Learning points}

Levamisole-adulterated cocaine can cause retiform purpura and neutropenia in the setting of chronic drug exposure.

- Any patient suspected of having antineutrophil cytoplasmic antibodies vasculitis should have a urine test for cocaine, and for levamisole, if cocaine is present.

- The mainstay of treatment is abstinence from cocaine, 'especially levamisole'.

- Early recognition and treatment with steroids can result in complete resolution of skin lesions.
Emerging cases of associated glomerulonephritis have also been reported. Treatment includes abstinence from cocaine and supportive therapy, which will usually lead to resolution of cutaneous symptoms, as seen in our patient. Immunological abnormalities generally start improving within 2-14 months after withdrawal of levamisole. ${ }^{1}$ The use of high-dose glucocorticoids is growing in popularity among those who suffer from severe necrotic lesions. ${ }^{2}$

Contributors PAD was responsible for the literature search, images acquired, patient consent to publish images and generation of the original manuscript. NB was responsible for review of the original manuscript and any revisions made to the original manuscript. AA-K was responsible for the review and approval of the final manuscript, and any revisions made to the final manuscript.

Competing interests None declared.

\section{Patient consent Obtained.}

Provenance and peer review Not commissioned; externally peer reviewed.

\section{REFERENCES}

1 Carlson AQ, Tuot DS, Jen $K Y$, et al. Pauci-immune glomerulonephritis in individuals with disease associated with levamisole-adulterated cocaine: a series of 4 cases. Medicine (Baltimore) 2014;93:290-7.

2 Carter MR, Amirhaeri S. p-ANCA-associated vasculitis caused by levamisole-adulterated cocaine: a case report. Case Rep Emerg Med 2013:2013:878903.

3 Pendergraft WF III, Niles JL. Trojan horses: drug culprits associated with antineutrophil cytoplasmic autoantibody (ANCA) vasculitis. Curr Opin Rheumatol 2014;26:42-9.

Copyright 2015 BMJ Publishing Group. All rights reserved. For permission to reuse any of this content visit http://group.bmj.com/group/rights-licensing/permissions.

BMJ Case Report Fellows may re-use this article for personal use and teaching without any further permission.

Become a Fellow of BMJ Case Reports today and you can:

- Submit as many cases as you like

- Enjoy fast sympathetic peer review and rapid publication of accepted articles

- Access all the published articles

- Re-use any of the published material for personal use and teaching without further permission

For information on Institutional Fellowships contact consortiasales@bmjgroup.com

Visit casereports.bmj.com for more articles like this and to become a Fellow 